\title{
Эволюция средней поперечной энергии электронов, эмитированных p-GaAs(Cs,O) фотокатодом, в процессе его кислород-индуцированной деградации
}

\author{
Г.Э. Шайблер ${ }^{1,2}$, С.Н. Косолобов ${ }^{1}$, А.С. Терехов ${ }^{1}$, L.B. Jones ${ }^{3,4}$, B.L. Militsyn ${ }^{3,4}$, T.C.Q.Noakes ${ }^{3,4}$ \\ ${ }^{1}$ ИФП СО РАН, Новосибирск, 630090, Лаврентьева, 13 \\ ${ }^{2}$ Новосибирский Государственный Университет, Новосибирск, 630090, Пирогова, 2 \\ ${ }^{3} A S T e C$, STFC Daresbury Laboratory, Warrington, Cheshire, WA4 4AD, UK \\ ${ }^{4}$ Cockcroft Institute of Accelerator Science and Technology, Warrington, WA4 4AD, UK \\ тел:+7 (383) 330-98-74, факс:+7 (383) 333-27-71, эл.nочта: scheibl@isp.nsc.ru
}

DOI 10.34077/RCSP2021-70

Фотокатоды на основе GaAs широко используются в качестве источников электронов в ускорителях [1]. Энергетическое распределение эмитированных электронов определяет параметры электронного пучка, в частности средняя поперечная энергия (МТЕ) является одним из параметров, которые определяют яркость пучка электронов (плотность электронов в 6-мерном пространстве координат и импульсов). Несмотря на большое количество литературы, в которой представлены измерения МТЕ для фотокатодных источников электронов, используемых в ускорителях, информации об изменениях MTE во время деградации фотокатода мало. Учитывая, что деградация фотокатода неизбежна во время работы источника электронов ускорителя, исследование эволюции МТЕ во время деградации фотокатода и механизмов, лежащих в основе этого процесса, представляет практический интерес для оценки изменений качества пучка во время работы ускорителя. Мы изготовили p-GaAs(Cs,O) фотокатод, активированный до состояния эффективного отрицательного электронного сродства $(\chi *<0)$, а затем подвергли его деградации точно контролируемыми дозами кислорода. Этим мы смогли смоделировать одну из возможных траекторий деградации фотокатода во время работы ускорителя и отследить последующие изменения в разбросе электронов по энергиям. Измерения распределений эмитированных электронов по продольной (к нормали к поверхности фотокатода) и поперечной компонентам энергии проводились с помощью спектрометра TESS [2]. Основой спектрометра являлся детектор, состоявший из системы трех сеток, сборки из двух микроканальных пластин (МКП) и люминофорного экрана. Детектор параллелен поверхности фотокатода и находился на расстоянии

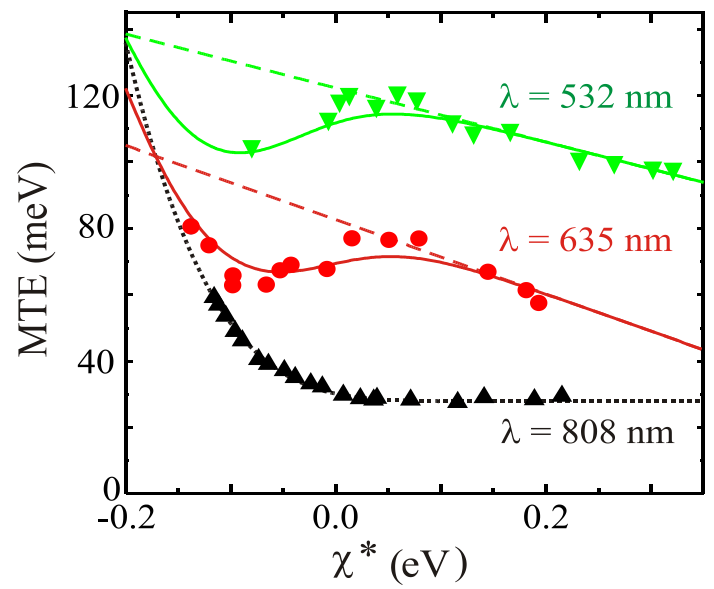

23 мм от него. Фотокатод освещался в центральной области со стороны эмитирующей поверхности световым пятном с размерами, не превышающими 200 мкм. Распределения электронов по продольной компоненте энергии измерялись методом задерживающего потенциала, прикладываемого к промежутку первая сетка - вход первой МКП. Смещение электрона в плоскости, параллельной поверхности фотокатода, при его движении от фотокатода к детектору зависит от поперечной компоненты энергии электрона, что позволяет вычислять распределение электронов по поперечной компоненте энергии из анализа формы интенсивности свечения люминофорного экрана. Было проведено три цикла экспериментов, отличавшихся длиной волны падающего на фотокатод света $\lambda=808$ нм, $\lambda=635$ нм и $\lambda=532$ нм. Из эволюции распределений эмитированных электронов по продольной компоненте энергии мы определили зависимость эффективного электронного сродства $\chi^{*}$ от кислородной дозы. Это позволило определить зависимость средней поперечной энергии от величины отрицательного электронного сродства, представленную на рисунке. Видно, что при освещении фотокатода светом с $\lambda=808$ нм МТЕ монотонно снижается с увеличением $\chi^{*}$, а для $\lambda=635$ нм и $\lambda=532$ нм поведение МТЕ неожиданно оказалось немонотонным. Такая немонотонность объясняется изменением долей термализованных и нетермализованных (горячих) электронов в общем числе эмитированных электронов при изменении эффективного электронного сродства. Результаты работы представлены в [3]. Работа выполнена при поддержке РФФИ (проект 19-02-00517).

\section{Лumepamypa}

[1] D.H. Dowell et al. // Nuclear Instrum. and Methods A. 2010. V.622. P.685-697.

[2] L.B. Jones et al. // J. Appl. Phys. 2017, V.121. P.225707.

[3] L.B. Jones et al. // J. Phys. D: Appl. Phys. 2021, V.54. P.205301. 